\title{
Optimization in Water Management for Sustainable Irrigated Rice Production in Central Côte d'Ivoire Under Rainfall Variability
}

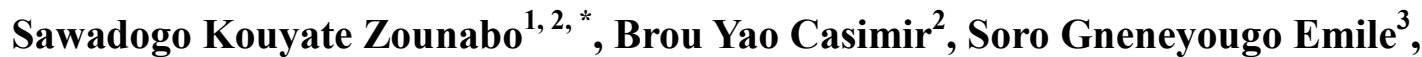 \\ Goula Bi Tié Albert ${ }^{3}$, Traore Farid ${ }^{4}$ \\ ${ }^{1}$ Agropastoral Management Institute, Peleforo Gbon Coulibaly University, Korhogo, Côte d'Ivoire \\ ${ }^{2}$ Joint Research and Innovation Unit of Agronomic Science and Rural Engineering, Houphouet Boigny National Polytechnic Institute, \\ Yamoussoukro, Côte d'Ivoire \\ ${ }^{3}$ Geosciences and Environment Laboratory, Nangui Abrogoua University, Abidjan, Côte d'Ivoire \\ ${ }^{4}$ Institute of Environment and Agricultural Research, Ouagadougou, Burkina Faso
}

Email address:

kouyatezen@gmail.com (S. K. Zounabo), ycasimir.brou@gmail.com (B. Y. Casimir), ge_soro@yahoo.f(S. G. Emile), goulaba2002@yahoo.fr (G. Bi T. Albert), farid.traore@yahoo.fr (T. Farid)

${ }^{*}$ Corresponding author

\section{To cite this article:}

Sawadogo Kouyate Zounabo, Brou Yao Casimir, Soro Gneneyougo Emile, Goula Bi Tié Albert, Traore Farid. Optimization in Water Management for Sustainable Irrigated Rice Production in Central Côte d'Ivoire Under Rainfall Variability. Agriculture, Forestry and Fisheries. Vol. 9, No. 3, 2020, pp. 86-96. doi: 10.11648/j.aff.20200903.16

Received: December 19, 2019; Accepted: June 1, 2020; Published: June 17, 2020

\begin{abstract}
Irrigation is a major challenge of food self-sufficiency because of the demographic conditions of Ivorian cities, combined with climate variability. The aim of this study is to analyze and optimize practices management of rice irrigation in Nanan, at the central Côte d'Ivoire under rainfall variability. Methodological approach adopted was multidisciplinary and participatory. Climatic, agro-pedological, hydrometric and sociological data was used in this study. Results showed that rainfall variability is a reality and is characterized by alternating dry and wet periods. Agricultural practices analysis showed low value of crop intensity with $108 \%$ and $88 \%$ in 2016 and 2017 respectively. Irrigation efficiency is estimated at $37 \%$. The results also showed a mismatch between water withdrawals and water needs, which vary between $4 \%$ and $80 \%$. A poor annual distribution of rice transplanting with almost no transplanting during the first cycle was observed. Facing to these malfunctions, a reorganization of farming practice was recommended. This starts with harmonization of transplanting date and implementation of optimized water management methods. The periods from March to April, and September to October was identified as the optimal transplanting periods for the first and second cycles respectively. In addition, Height-Flow -Turn of Valve curve was carried out to help valve manager estimate water needed quantities. Finally, telephone fleet was proposed as communication way, to improve water distribution method by rotation between rice farmers.
\end{abstract}

Keywords: Irrigation, Rice, Rainfall Variability, Water Management, Nanan

\section{Introduction}

Climate change that began in Sahelian countries in the 1970 s has spread to humid countries along the Gulf of Guinea [1]. In Côte d'Ivoire, this climate variability has been observed through recurrent droughts, irregular rain changes in season, reduction of arable land, coastal erosion and floods [2]. This situation is taking place in an environment affected by strong population growth. As consequence, a growth in food production is necessary to meet the ever-increasing demand [3]. Large part of this increase will come from intensive and sustainable agriculture, of which irrigation will be one of the pillars [4]. Thus, development of irrigation remains an important issue for food security. However, it appears that irrigation systems are themselves vulnerable to climatic hazards. One of the answers to this dilemma in recent decades has been 
the control of surface water resources to limit climate uncertainty. As a result, Ivorian authorities, through several development projects, initiated the implementation of agricultural policy of food self-sufficiency since 1970, in which rice plays a key role. Several hydro-agricultural developments have been carried out in central Côte d'Ivoire, the main purpose of which is rice production. Forty years later, the government disengaged himself from the production system and liberalized the sector, which was previously supported [5]. However, in order to achieve food self-sufficiency, it seems more than necessary to increase the irrigated areas through the development of new perimeters but above all, to maintain the developed perimeters in a sustainable way. For that, it is important to understand the dysfunctions on these existing irrigations areas, and the implementation of the reliable and applicable management methods in a climate variation context. In addition, the significant variations in water levels of dams in recent years, including complete emptying and the cessation of rice farming activities in some areas, highlight the vulnerability of these developments. Moreover, many studies had showed that main changes in irrigation management are essential to access optimize water use and sustain irrigation development [6-9]. The time has come for sustainable water management of reservoirs to guarantee production regardless of rainfall regime. This requires an analysis of performance of the perimeter and implementation of sustainability methods applicable in a context of climate variation. This will involve implementing techniques to facilitate access to information, the choice of optimal transplanting date and the estimation of the quantities of water needed for irrigation. This approach is based on the analysis of the rainfall regime and its impact on irrigation water needs according to the transplanting date.

\section{Material and Methods}

\subsection{Presentation of the Study Area}

Study area is the perimeter of Nanan. This area is located in Yamoussoukro, in the central of Côte d'Ivoire (Figure 1). Study area covers 0.32 square kilometers. It is supplied with water by Nanan dam with capacity of $600,000 \mathrm{~m}^{3}$. It belongs to the equatorial transitional climate characterized by an alternation of two rainy seasons (small rainy season and large rainy season) and two dry seasons (large dry season and small dry season). Annual rainfall varies between $857 \mathrm{~mm}$ to $1512 \mathrm{~mm}$ with an inter-annual average of $1142 \mathrm{~mm}$ over the period 1975 to 2015 . The average temperature varies between $28^{\circ} \mathrm{C}$ and $24^{\circ} \mathrm{C}$. The average relative humidity varies between 64 and $82 \%$, with a minimum in January and a maximum in July.

\subsection{Data}

Climatic data collected include rainfall, potential evapotranspiration, relative humidity, temperature, wind speed, and sunshine duration. These data are daily for the period January to December 2017 and monthly for the period 1975-2015. It come from the synoptic station of Yamoussoukro and is collected from the national meteorological service (SODEXAM). Limnimetric data was obtained from two daily readings of water level from dam to the limnimetric station ( 8 am and $18 \mathrm{pm}$ ) from January 01 to December 31, 2017. Hydrometric data was obtained by gauging the water of the primary channel with the "Moulinet".

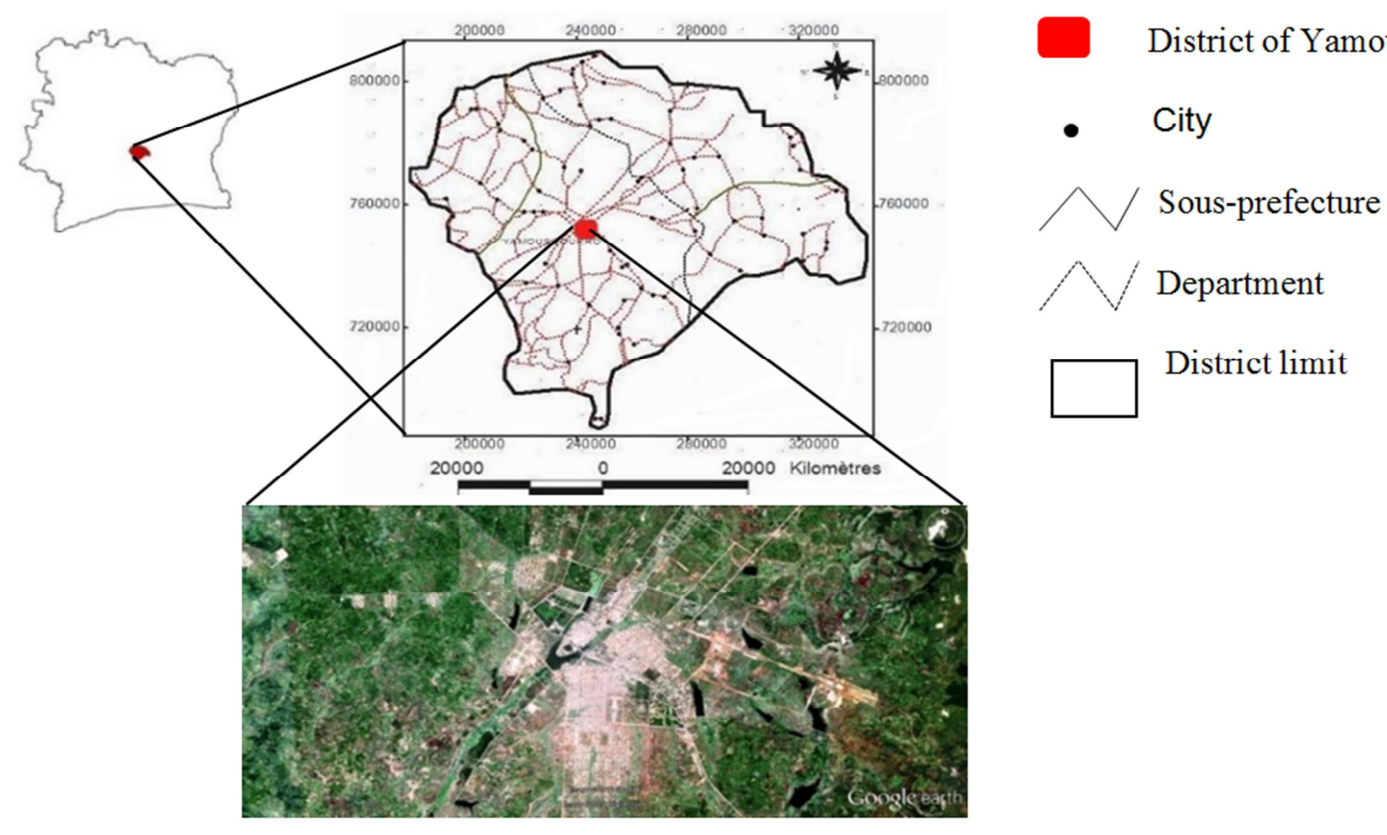

Figure 1. Situation map of the Nanan perimeter.

Agro-pedological data related to crop coefficients, maximum rooting depths of rice and soil types. They are based 
on the bibliography, in particular FAO Bulletins 24 and 56 [10-12] for root depths. The rooting depth for irrigated rice is in the range of 0.5 to $0.70 \mathrm{~m}$. The soils are clayey with clayeysand-sand-silt silt covering 20 to $30 \mathrm{~cm}$ thick, sandy-clayey-silt passing to sandy with a ferralitic material covering 30 to $60 \mathrm{~cm}$ thick [10]. The variety of rice grown on the Nanan perimeter is WITA 9 "Oriza Sativa (Indica)" with a 120 days cycle. The sociological data based on surveys and interview with rice farmers and the valve manager respectively.

\subsection{Methods}

The methodology used was multidisciplinary. It is a combination of hydrological, hydrometric, agronomic and sociological analysis.

\subsubsection{Method for Estimating the Flows in the Watershed}

From water point tower of downstream of the right bank, installed at the entrance of irrigation area, a $200 \mathrm{~mm}$ diameter pipe supplies the channel. This type of taking water is as water taking by orifice calibrated and carried out in a large tank (the dam) (Figure 2). The study of water samples required a follow-up of the daily opening and closing hours of the valve by the valve manager and the reading of the water level of the dam. The water is taking out with different turns of the valve. A calibration of the valve has been necessary before measurements. In total, the valve makes 13 turns to be at the maximum of its flow rate. The gauging sessions is carried out according to the recommendations of OMM [14]. It was used to estimate the daily flow characteristics and the flow for different turns of valve. Then, the flow value obtains are used to estimate the flow coefficient and determine the flows of ungauged days.

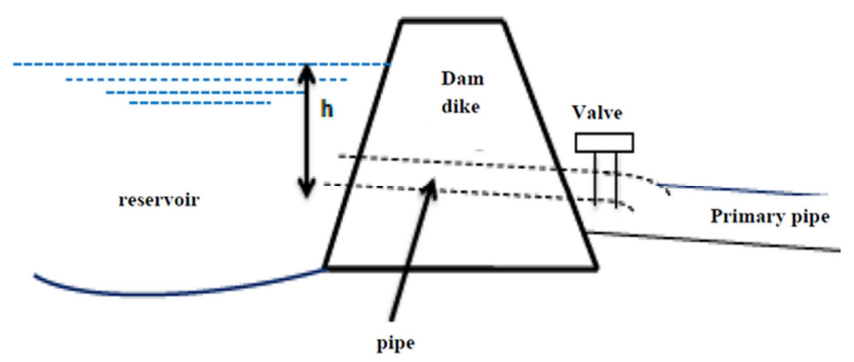

Figure 2. Principle of water withdrawal from the dam.

The gauging sessions is carried out according to the recommendations of OMM [14]. It was used to estimate daily flow characteristics and flow for different turns of valve. Then, the flow value obtains are used to estimate the flow coefficient and determine the flows of ungauged days.

Relationship has been established between the measured flow rate and the number of the valve revolutions according to $(1)$.

$$
\mathrm{Q}=\mathrm{f}(\mathrm{n})
$$

Where,

$\mathrm{n}$ is the number of valve turns

Then the irrigation water withdrawal rates were determined by the equation derived from Torricelli's law for circular orifices (Figure 2). This allowed determining the value of the flow coefficient [15] (2).

$$
\mathrm{Q}=\mathrm{C} * \mathrm{~S} * \sqrt{2 g h}
$$

Where,

C, flow coefficient (depended on the shape of the orifice) without dimension,

$\mathrm{S}$, orifice section in $\mathrm{m}^{2}$

g, acceleration of gravity, $9.81 \mathrm{~m} / \mathrm{s}^{2}$

$\mathrm{h}$, the water load above the orifice in $\mathrm{m}$

Based on this knowledge of the flow considered as the maximum flow for a total opening of the valve (maximum number of turns $=13$ ), then the unit flow per valve turn is determined and then the flow of day $\mathrm{j}$ (3).

$$
\mathrm{Q}_{\mathrm{j}}=\frac{\mathrm{c} * \mathrm{~S} * \sqrt{2 g h}}{13} * n_{j}
$$

Where,

Qj representing the flow of day $j$

$\mathrm{nj}$, the number of valve turns of day $\mathrm{j}$

\subsubsection{Hydro-climatic Analysis}

Hydro-climatic study is based on the analysis of the fluctuations of rainfall and flow patterns over 1975-2015. An analysis is performed using the Nicolson method [16]. This method has been successfully applied on series of rainfall and flows in Africa [17-20]. To eliminate the internal variability of each unit, analyzes often focus on standardized values (indices) that measure a deviation from an average basis over a long period.

\subsubsection{Hydro Rainfall Indices}

The indices studied here measure the differences between the variables studied over an average basis over a long period. They can differentiate the dry years or decades/loss and wet/surplus. The calculation of the Standardized precipitation index (SPI) was developed [21] (4).

$$
\mathrm{SPI}=\frac{(P i-P m)}{\propto}
$$

Where,

Pi: Total annual precipitation of year $\mathrm{i}$

Pm: Average inter-annual precipitation over the calculation period

$\alpha$ : Standard deviation of inter-annual rainfall over the calculation period;

\subsubsection{Principle of the Low-Pass Filter Hanning Order 2}

The method of the low-pass filter of order 2 or Hanning weighted moving averages method was used to weight the rainfall totals. Indeed, the non-recursive low-pass filter Hanning 2nd order filters the seasonal variations by calculating weighted rainfall totals. The details of this method are given [22].

\subsubsection{Irrigation Water Needs}

A crop's water requirements depend on a combination of 
crop, soil and climate parameters. The climate is the most important parameter in the evapotranspiration of crops and therefore their water needs [10]. FAO's CROPWAT 8.0 software was used to estimate water requirements. It is a decision support tool for irrigation planning and management developed by FAO's Land and Water Development Division [23]. Calculations of evapotranspiration and water requirements was based on the Penman-Monteith method and the use of the cultural coefficient [11]. The USDA-SCS method was used to calculate effective rainfall [24]. The Estimation actual water requirements required monitoring of rice farmers' agricultural activities through transplanting dates and areas planted over a year (2017).

\subsubsection{Analysis of Nanan Perimeter Performance}

Four indicators was used to analyze the performance of the rice irrigation area. These are the crop intensity, the adequacy of needs and taking water, efficiency of irrigation and the monthly occupancy rate of the perimeter.

\section{i. Crop Intensity}

Crop intensity (CI) provides information on the current occupancy level of the perimeter and allows deducing performances of its exploitation. Crop intensity (CI) is a key indicator. It corresponds to the ratio between the annual area cultivated and the exploitable area $[25,26]$.

$$
\mathrm{CI}(\%)=\frac{s_{e}}{s_{a}} * 100
$$

Where

$\mathrm{S}_{\mathrm{e}}$ : annual area cultivated (ha)

$\mathrm{S}_{\mathrm{a}}$ : exploitable area (ha)

When the value of the CI is greater than $150 \%$ then it is considered medium to high and for the CI less than $150 \%$ then it is low [25].

\section{ii. Adequacy Between Irrigation Water Needs and Levels}

The study of appropriateness between irrigation water needs and taken is carried out by comparing the real water needs of the rice simulated using CROPWAT 8.0 software and increased by considering the minimum irrigation efficiency of gravity irrigation and the taken water during the same period.

\section{iii. Irrigation Efficiency}

Irrigation efficiency is a critical factor in irrigation water management. It is a measure of the effectiveness of irrigation [27]. The American Society of Agricultural and Biological Engineers has defined irrigation efficiency as the ratio of the average depth of irrigation water that is beneficially used to the average depth of irrigation water applied, expressed as a percent [28]. Understanding irrigation efficiency is fundamental to improving water management at the farm [27]. Irrigation efficiency was calculated with (6) used by [29] and [8] in the evaluation of irrigated perimeters performance.

$$
\mathrm{E}_{\mathrm{Irr}}=\frac{B_{m}}{P_{m}} * 100
$$

Where,

$\mathrm{E}_{\text {Irr }}$ : Irrigation Efficiency

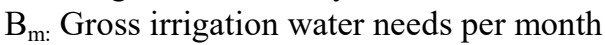

$\mathrm{P}_{\mathrm{m}}$ : Monthly water withdrawal for irrigation

\section{iv. Monthly Occupancy Rate of the Perimeter}

Monitoring the dates of rice transplanting over a year made it possible to assess the monthly occupancy rate of the perimeter. It was determined from (7):

$$
\operatorname{Tr}=\frac{S_{m}}{S} * 100
$$

Where,

Sm: the area cultivated in the month $\mathrm{m}$

$\mathrm{S}$ : the total area cultivated during the year

\subsubsection{Optimization of Irrigation Water Management}

Optimizing irrigation water management involves, on the one hand, choosing the transplanting date and, on the other hand, choosing an efficient method for managing irrigation withdrawals.

\section{i. Choice of the Optimal Transplanting Period}

Climate is one of the most important factors influencing crop water requirements [10]. Irrigation helps to compensate the crop's water needs that are not met by rainfall. Thus, the approach the optimal transplanting date choosing according to the rainfall regime is based on this role of rain in reducing irrigation needs. This period allow to take full advantage of rainfall inputs in order to better manage the water of the tank. It is obtained by considering the wettest year, the driest year of the observation period according to the value of the precipitations standardized index. Also the average of the observed data is taken into account. From these three rainfall data considered as extreme and median, irrigation water needs are determined for different transplanting dates corresponding to the 15th of each month. The optimal period then corresponds to the period for which irrigation water needs are very little influenced by the rainfall regime (dry, wet, and average).

\section{ii. Management Practice on the Perimeter}

Implementation of the taken water management method was done by simulating the valve turns according to the dam's water level and setting up a means of communication between farmers. It was made possible thanks to the participation of farmers in defining their problems and decision-making through surveys and interviews. Indeed, the participatory method seems to be better suited to the study of water management and optimization of small dams. In fact, the water use practices are closely linked to the behaviors of users who have a better understanding of their capacity to make changes. The questions raised during this survey relate to sociologic aspects, the problem of irrigation water management and the proposed solutions. Twenty-two (22) rice farmers were identified and 20 of whom were present during the survey in August 2017. These surveys were supplemented by direct field observations of water 
management practice. In addition, an interview was conducted with the valve manager regarding the problem of quantifying the needs water to be provided and the management of the water on the plot.

\section{Results}

\subsection{Flow Rate and Valve Turn Ratio}

The calculation of flows according to the different water levels of the dam made it possible to determine flow coefficient of the orifice supplying the rice area (Table 1).

Table 1. Variation in orifice flow coefficient.

\begin{tabular}{llll}
\hline Parameters & \multicolumn{4}{l}{ Measured values } \\
\hline Dam water level $(\mathbf{m})$ & $\mathbf{4 . 0 2}$ & $\mathbf{4}$ & $\mathbf{4 . 6}$ \\
\hline $\mathrm{S}(2 \mathrm{gh}){ }^{1 / 2}\left(\mathrm{~m}^{2}\right)$ & 0.279 & 0.298 & 0.278 \\
Flow rate $(13$ turns $)\left(\mathrm{m}^{3} / \mathrm{s}\right)$ & 0.119 & 0.121 & 0.128 \\
$\mathrm{c}$ (Flow coefficient) & 0.428 & 0.435 & 0.431 \\
\hline
\end{tabular}

Values of the orifice coefficients obtained vary between 0.428 and 0.435 with an average of 0.43 . A relative consistency is observed between these different values. The relationship between the measured flow rates and the number of valve turn for the different gauging dates gives a linear function of origin 0 , equation $\mathrm{Q}=0.011^{*} \mathrm{x}, \mathrm{x}$ being the number of valve turn (Figure 3). This relationship is good with a determination coefficient $\mathrm{R}^{2}=0.97$. For a water level upstream $h$ in the dam, the unit flow rate (Flow per valve revolution) is a constant.

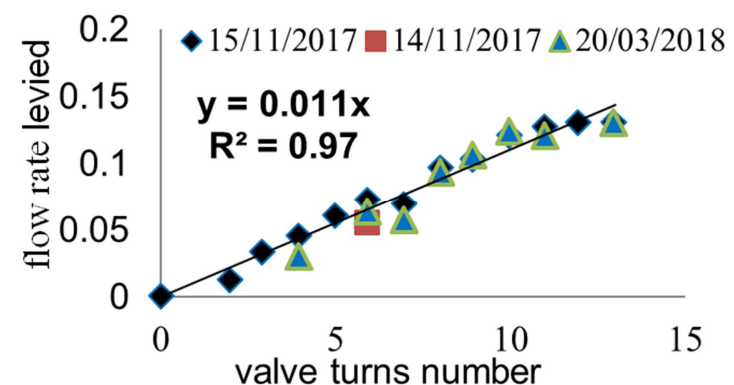

Figure 3. Relationship between the sample flow rate and the number of valve revolutions for different gauging dates.

\subsection{Characterization of Rainfall Variability}

Lowest Nicholson rainfall index is observed in 1983 (-1.6) and the highest in $2003(+2.5)$ (Figure 4). The evolution of the Nicholson index and the weighted index associated with seasonal elimination using the second order Hanning lowpass filter (Figure 5) highlighted the rainfall variability marked by two climatic periods, wet periods and dry periods. Dry periods are generally between the early 1975 and late 1992 and wet periods between the early 1993 and late 2010. They are followed by a dry period between the beginning of 2011 and the end of 2015. A breaking change was detected. There is an alternation of dry and wet years with a predominance of dry years during the period 1975-1992, with the lowest index observed in $1983(-1.70)$. The positive index is higher in the period 1993-2010, when the wettest year of the whole series is 2003 with an SPI of 2.20 (Figure 6).

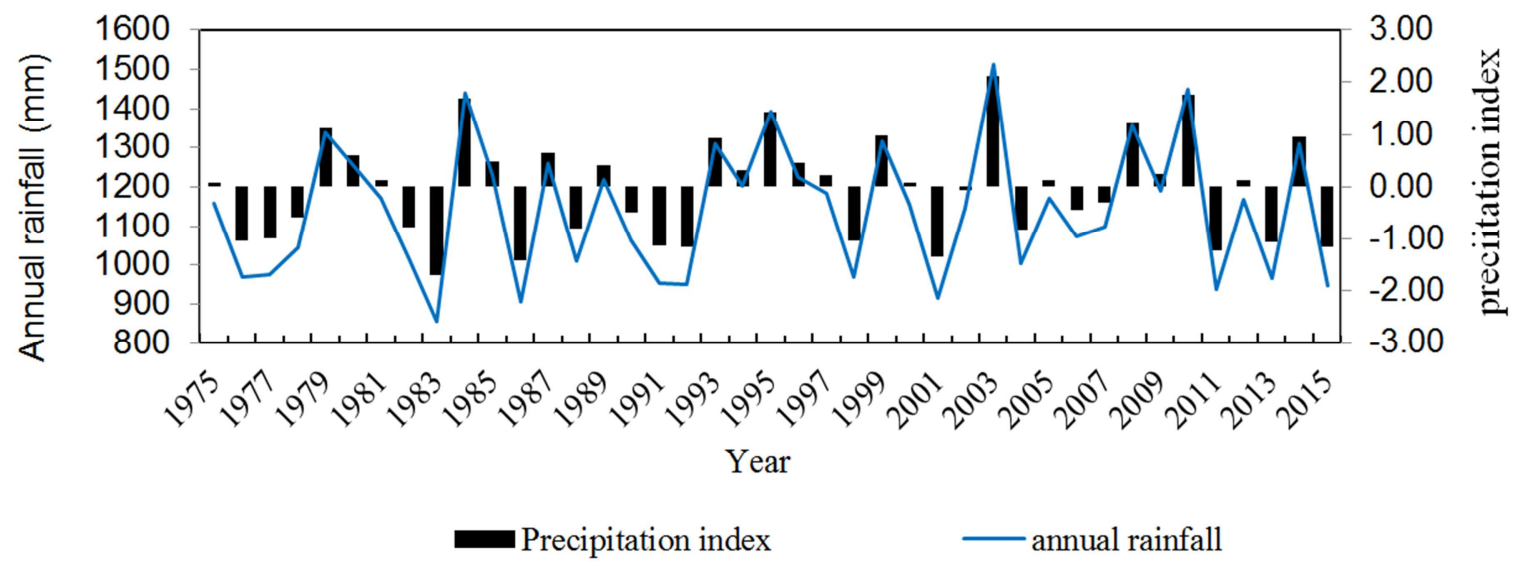

Figure 4. Evolution of Nicholson indices and inter-annual rainfall between 1975 and 2015.

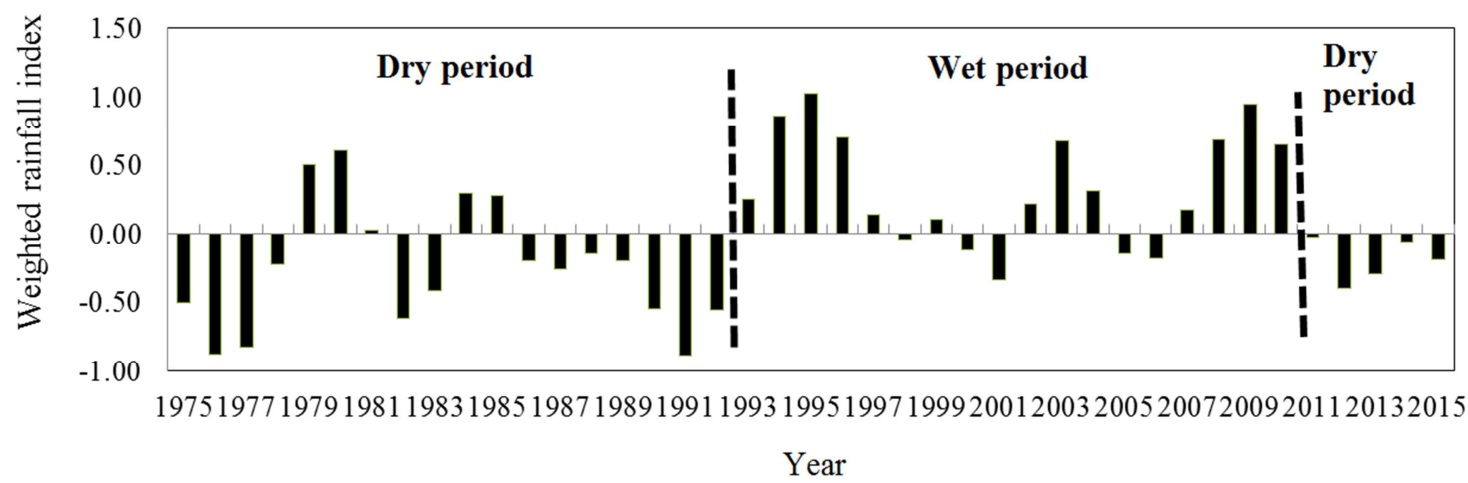

Figure 5. Hanning weighted rainfall indices of order 2 from Yamoussoukro station. 


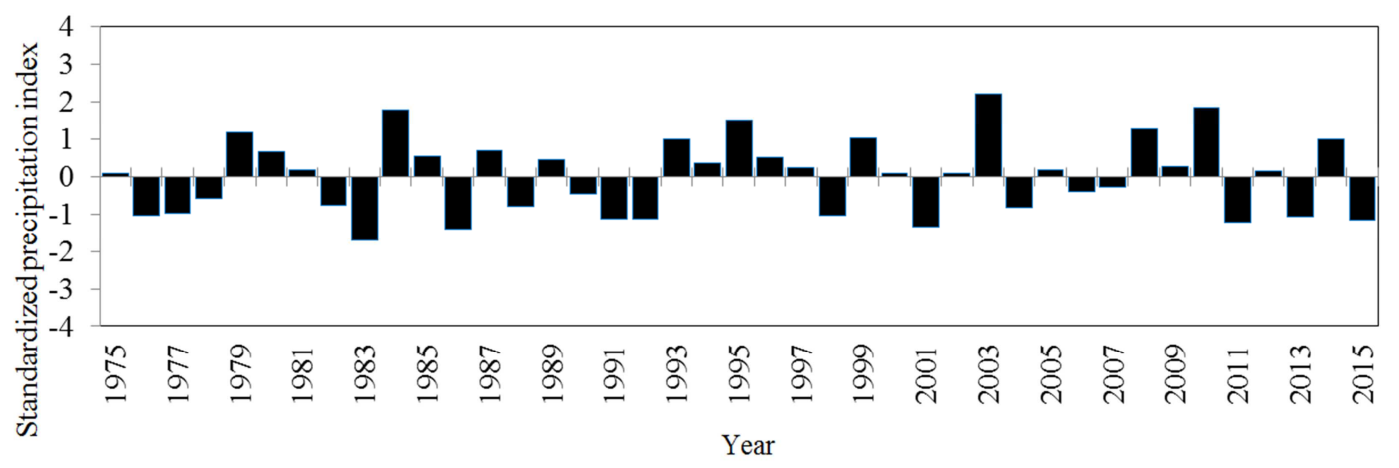

Figure 6. Standardized precipitation indices over the period 1975-2015 from Yamoussoukro station.

Table 2. Classification of SPI and their frequencies.

\begin{tabular}{llll}
\hline Gamme SPI & $\begin{array}{l}\text { Drought } \\
\text { category }\end{array}$ & $\begin{array}{l}\text { Total number } \\
\text { of year }\end{array}$ & Frequency \\
\hline 2.0 and over & Extremely wet & 1 & 1 time in 41 years \\
1.5 to 1.99 & Very wet & 3 & 1 time in 13 years \\
1 to 1.49 & Moderately wet & 5 & 1 time in 8 years \\
-0.99 to 0.99 & near normal & 22 & 1 time in 2 years \\
-1 to -1.49 & moderately dry & 9 & 1 time in 4 years \\
-1.5 to -1.99 & severely dry & 1 & 1 time in 41 years \\
-2 and less & extremely dry & 0 & 0 \\
\hline
\end{tabular}

More than $50 \%$ of the years in the series, i.e. 22 years, have near-normal rainfall with a frequency of occurrence of 1 year out of 2 (Table 2). The frequency of occurrence of dry years is much the same as the wet years. The rainfall situation is therefore very uncertain.

\subsection{Water Withdrawal for Rice Farming}

Water withdrawals to the rice area were determined during 2016 and 2017 (Figure 7). The observation is that the monthly withdrawals at the reservoir level vary between 40 $000 \mathrm{~m}^{3}$ and $120000 \mathrm{~m}^{3}$. However, the maximum values are observed in May for both years. The total volume withdrawn during the 2016 and 2017 seasons was $903601.8 \mathrm{~m}^{3}$ and 913 $785.6 \mathrm{~m}^{3}$ respectively.

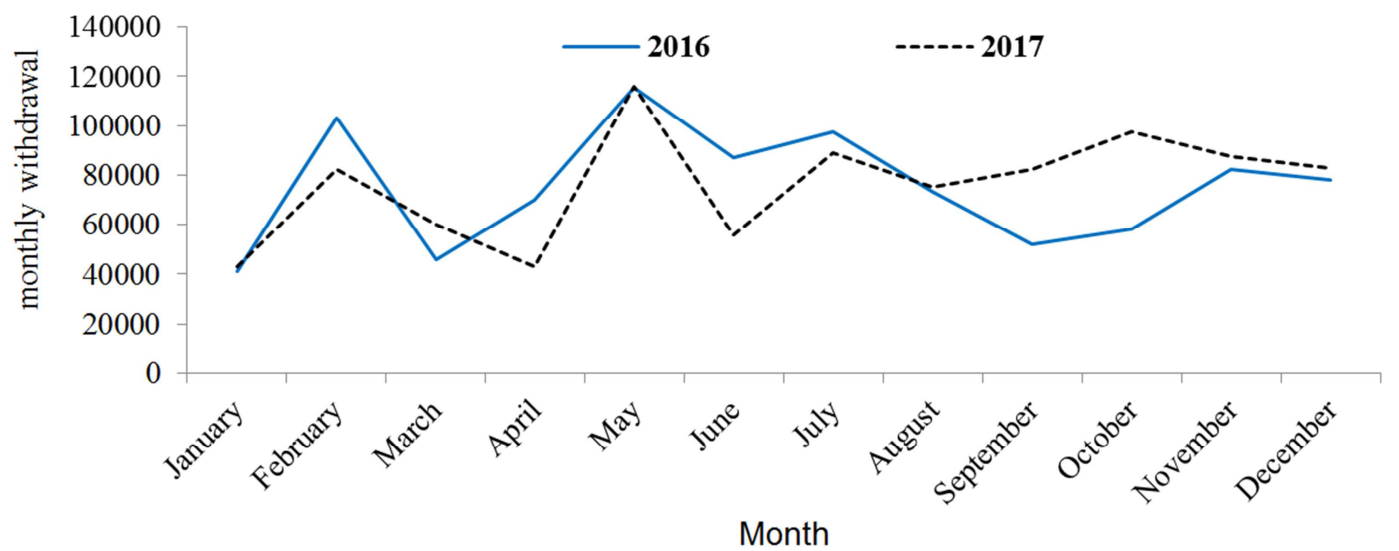

Figure 7. Monthly variation in water withdrawals to the rice area over the two years of measurements $(2016,2017)$.

\subsection{Performances of Nanan Perimeter}

\subsubsection{Crop Intensity}

Rice-cultivated areas in 2016 and 2017 are listed in Table 3. The crop intensities for 2016 and 2017 are $108 \%$ and $88 \%$ respectively.

Table 3. Crop intensity in 2016 and 2017

\begin{tabular}{llll}
\hline & $\mathbf{2 0 1 6}$ & $\mathbf{2 0 1 7}$ & \\
\hline Total area developed $\left(\mathrm{km}^{2}\right)$ & 0.35 & 0.28 & 88.54 \\
Crop intensity $\%$ & 108 & 84 & \\
\hline
\end{tabular}

\subsubsection{Adequacy of Water Needs and Withdrawals}

The differences between the two curves are very discontinuous. The monthly volumes taken are above the needs volumes except in June and October (Figure 8).

\subsubsection{Irrigation Efficiency}

Irrigation efficiency calculated per month and presented in Figure 9 is highly variable from month to month. It varies between $4 \%$ and $80 \%$ with average of $37 \%$. 


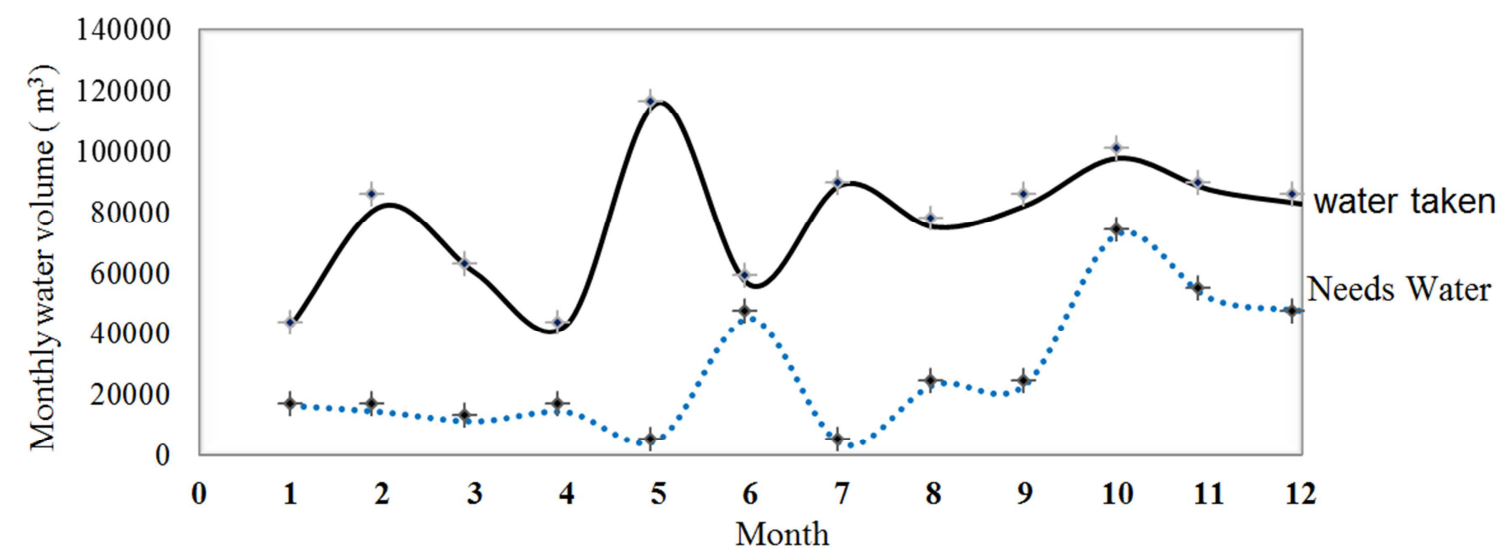

Figure 8. Comparison between monthly rice water requirements and withdrawals in 2017.

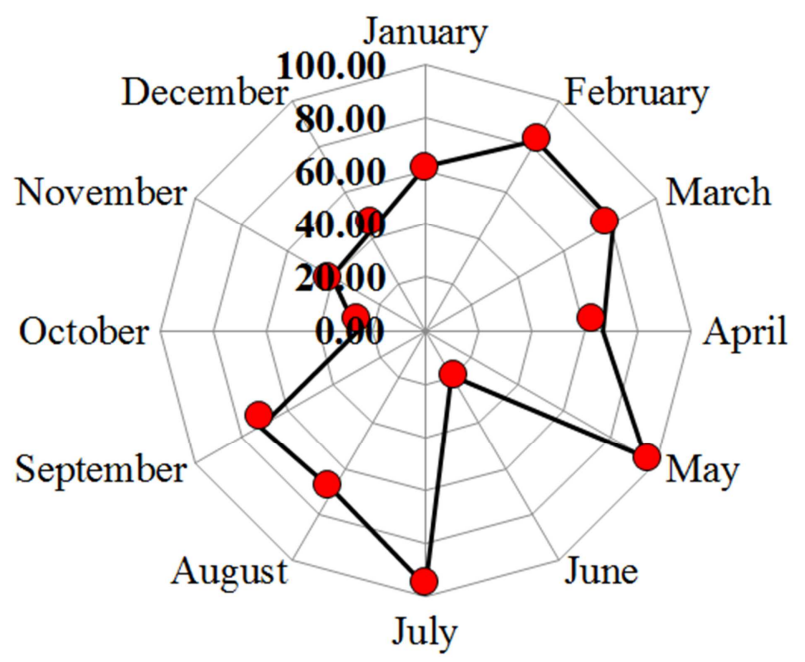

Figure 9. Monthly irrigation efficiency (\%).

\subsubsection{Monthly Occupancy Rate of the Plot}

Only the 2nd cycle is clearly distinguished by the highest land use rates in July, August and September (Figure 10). These months have respective rates of $17 \%, 32 \%$ and $36 \%$, i.e. a cumulative occupancy rate in the second cycle of $85 \%$. The first cycle is almost non-existent.

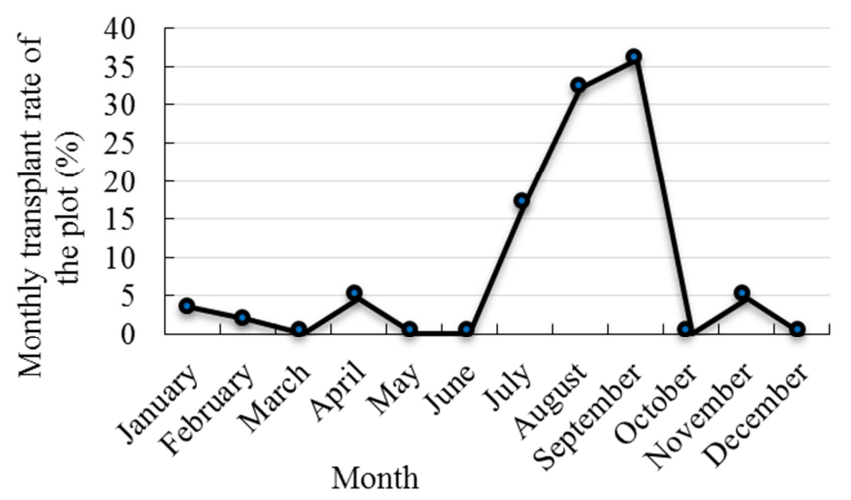

Figure 10. Monthly transplant rate of rice on the perimeter.

\subsection{Practical Organization of Irrigation}

The surveys revealed an atomization of the rice plots (Figure 11). Only $10 \%$ of the plots have an area of more than
2 hectares. Paradoxically, the water hands duration exceeds two days of irrigation for more than $65 \%$ of rice farmers (Figure 12). This watering takes place once a week for $70 \%$ of irrigators (Figure 13). Moreover, $65 \%$ of the reason for the poor distribution of water on the plot is due to human causes (Figure 14). This poor distribution results in a lack of water on some plots, difficulty in supplying and flooding on downstream plots. The poor organization of farmers for water distribution is the first human cause. It is one of the key factors in poor water management and can be explained by a lack of monitoring of the water hand and a total lack of attention in opening the valve.

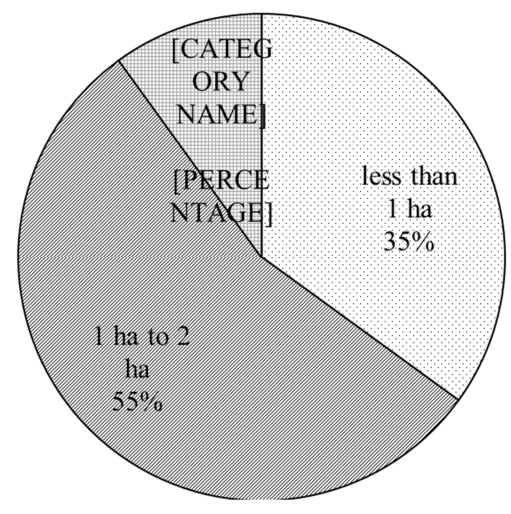

Figure 11. Cultivated areas' proportions

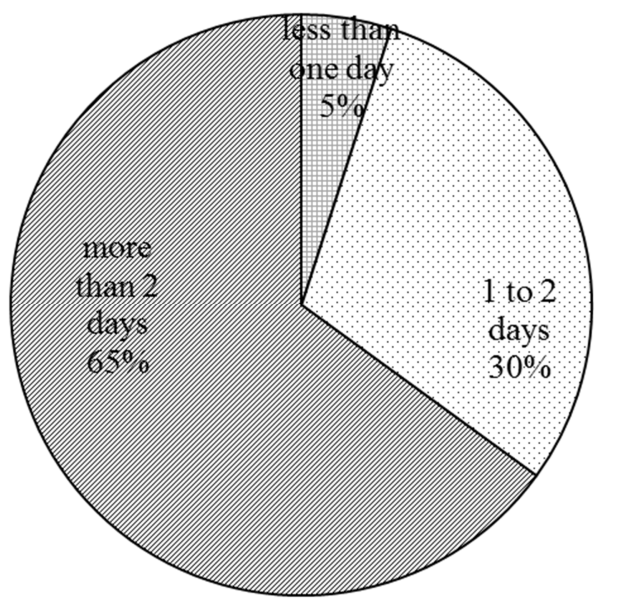

Figure 12. Rotation duration. 


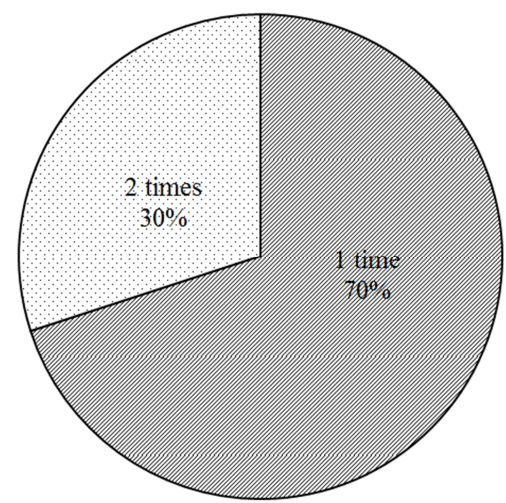

Figure 13. Proportion of weekly watering frequencies.

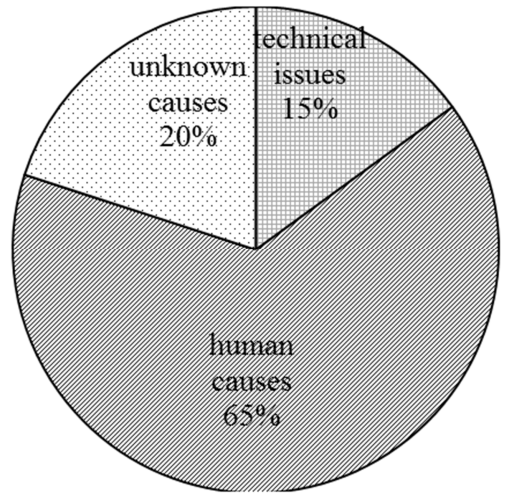

Figure 14. Causes of water unavailability on the plot.

During the interview with the valve manager, he noted that to allow all irrigators to feed their plot, the valve was opened every Monday at 8 a.m. and was only closed on Saturdays at 6 p.m. That is 6 days levies as planned but with a duration of 24 hours per day.

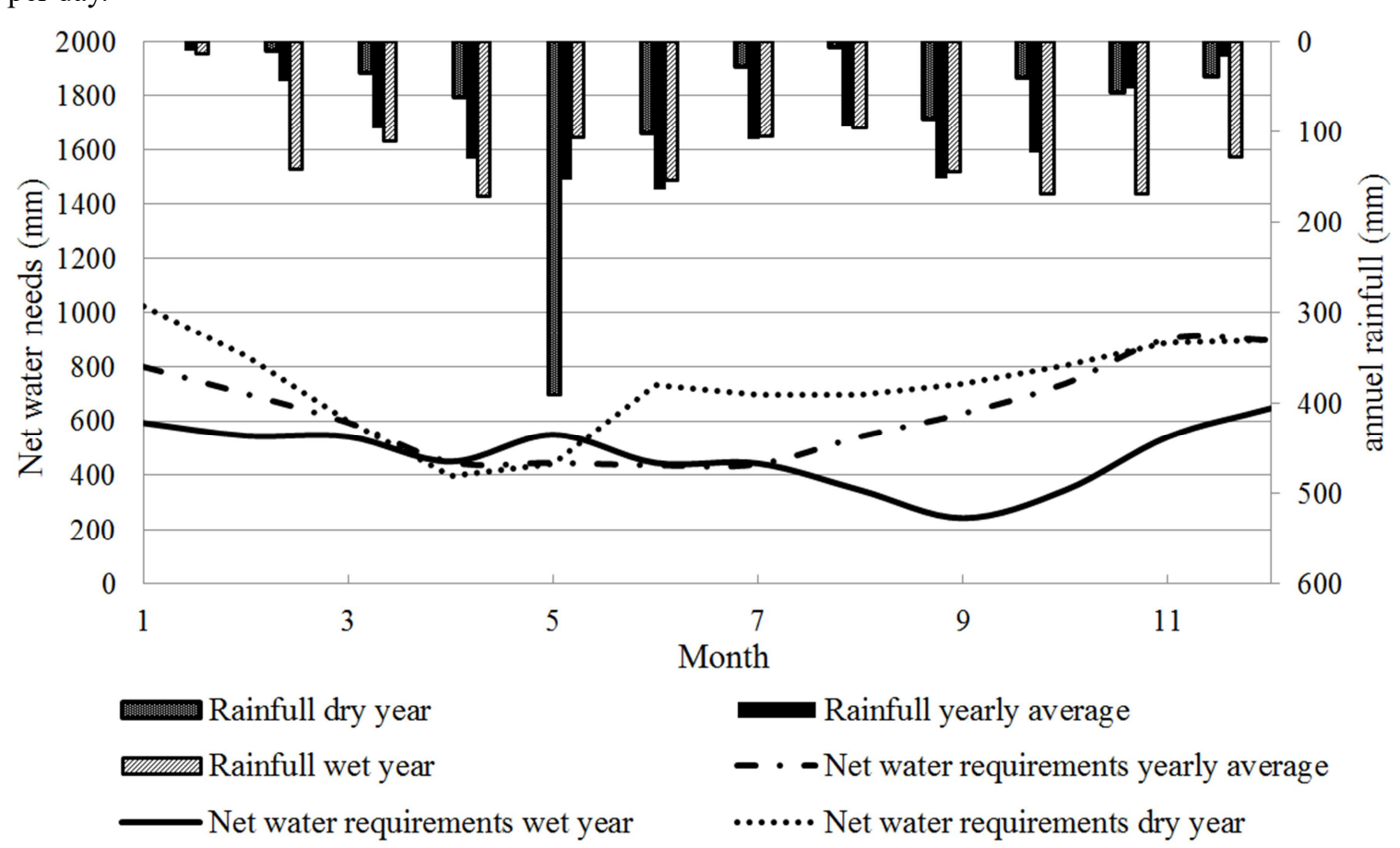

Figure 15. Variation in raw water requirements of rice by transplant date for different rainfall regimes (dry year (1983), average (1975-2015), wet year (2003)).

\subsection{Optimization of Water Management}

Optimization of water management requires the removal of identified malfunctions. The aim is to reorganize the two cycles by optimizing withdrawals and to propose a reliable method of water management on the perimeter.

\subsubsection{Determination of the Transplanting Date According to the Rainfall Regime and the Month}

Extreme periods (wet and dry) are the most likely to cause significant variations in water needs. Figure 15 shows the evolution of water needs and precipitation according to transplanting dates and rainfall patterns. The different curves of variation in rice water needs according to the three regimes have three levels of evolution: a decreasing phase between January to March, a practically constant phase in a humid year and a normal year between April and August and an increasing phase between August and December.

The rainy season (March-August) has an effect on irrigation water needs that decreases over this period. Thus, from March to April, the three curves are almost confused. Therefore, this period is not influenced by the rainfall regime and has poor irrigation water needs (between $400 \mathrm{~mm}-600$ $\mathrm{mm})$. So, it can be considered as the best transplanting period for the first cycle of the year.

On the other hand, the small rainy season has little influence on irrigation water requirements with the exception of the wet year when there is a reduction in irrigation water needs. However, by respecting the 120 days of the crop cycle and choosing a period that minimizes irrigation water needs, the period between September-October could ideally be proposed for the second cycle (under $800 \mathrm{~mm}$ ). 


\subsubsection{Optimization of Samples (Height - Flow - Turn Valve Curve)}

Harmonization of the transplanting period for all rice farmers is the second step of optimization water used after choosing the optimal transplanting period. Thus, it becomes easier to predict water needs and better manage openings, closures and valve turns by a simple method of reading water needs. To facilitate the work of the valve manager in defining valve turns as required, a relationship has been established between water demands (Required Flow), water height $(\mathrm{H})$ in the dam and the number of valve turns (Figure 16). For water level read at the limnimeter station, the correspondence is established with the curve. The different flow variations according to the water level in dam are linear.

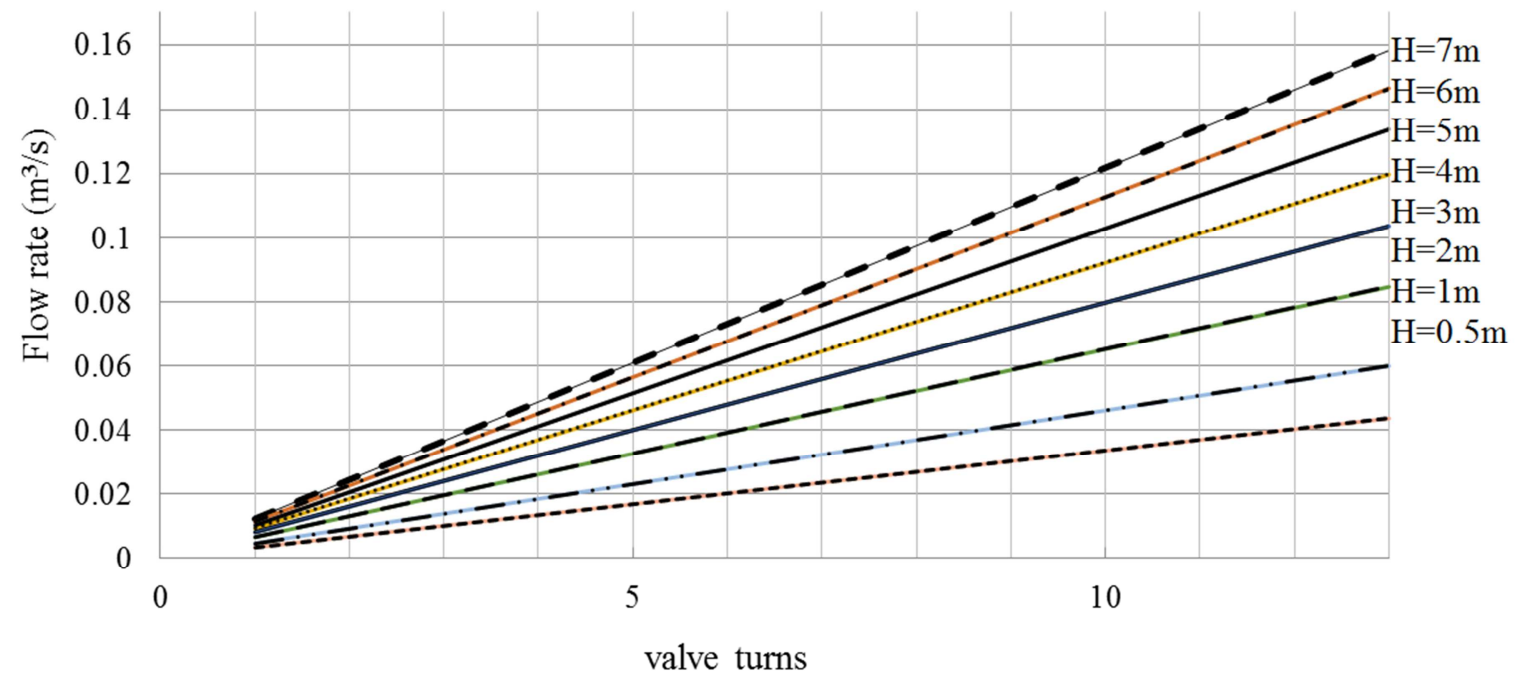

Figure 16. Height-Flow-Turn Valve Curve.

\subsubsection{Proposal of a Practical Management Method}

At the end of the analysis of the survey sheets, a meeting was organized with farmers to make a brief assessment and propose a method of water use management. Indeed, in view of the dysfunctions noted in water management and the reality of rainfall variability, a more rigorous management method must be implemented. Thus, the telephone fleet use is proposed to facilitate communication and information feedback for better organization of farmers. Farmers can subscript at $0.85 \$$ US and the maintenance costs $4.20 \$$ US per month free communication between them. This fleet also makes it possible to improve water distribution during rotation by removing the constraint of the absolute presence of the farmer on his plot during his water tour. Indeed, thanks to this means of communication, the prevented farmer can report it in time and allow the valve manager to request the replacement of him by another of his unit that is available. The fleet will also allow farmers to inform the valve manager of his farm work start so that their needs can be taken into account when the gates are opened. The leving period will be 6 days out of 7 at the rate of 10 hours per day, i.e. from 08 am to $6 \mathrm{pm}$ with a reorganization of the program in case of rainfall.

\section{Discussion}

The Hanning weighted rainfall indices of 2 order, applied to the rainfall series showed a climatic variability characterized by an alternating of wet and dry periods. This result is identical to those of the regions of Bocanda and
Dimbokro [30]. Through the application of reduced centred indices to rainfall series, they have shown an alternation of wet, normal and dry phases. In addition, an alternation of dry and wet periods since the beginning of the XXe century in non-Sahelian West and Central Africa was highlighted [31].

The estimation of the flow coefficient of the orifice supplying the primary channel showed that its value was almost constant at around 0.43 . This orifice is of the Borda type with a coefficient equal to 0.50 but with a lower value. This low value is probably due to the turbulence created at the outlet of the orifice, at the level of the dissipation basin located at the inlet of the primary channel. In the case of Nanan dam, the flow coefficient is 0.43 and can be used to estimate the flows taken from the right bank primary canal for rice cultivation. Thus, the relationship between the flow measured at the channel inlet and the number of valve revolutions shows a linear relationship. This linearity allows the flow rate to be estimated for a given number of valve revolutions and facilitates the monitoring of levies. In addition, the analysis of water withdrawals over the two years of monitoring gives very similar annual volumes. This will be explained by the definition of a leving logic for rice cultivation defined and monitored by the valve manager. This logic is independent of the actual water needs of the rice. However, this attitude can lead to excessive taking water. Indeed, the withdrawal rule must meet both the need to compensate for water not satisfied by rain and the respect of rotation between irrigators.

The crop intensity values obtained during the two monitoring years are well below the $150 \%$ reference value 
[25]. It highlights an under-exploitation of the rice growing area. This low value of crop intensity was explained by the decrease in water availability of the dam during the first cycle [26]. This is likely to create discouragement and abandonment of rice irrigation areas. The comparison between water withdrawals for irrigation and the actual water needs of rice in 2017 shows differences of up to twice. There is no relationship between monthly levies and simulated actual needs, the former always being higher than the latter. It confirms the anarchy in the leving and waste, at the discretion of the valve manager. However, significant difference in May would be justified by the tank emptying decided each year for fear of an overflow whichever tank water quantity. The low efficiency of irrigation, which averages $37 \%$, justifies the poor water management described above. The efficiency ranges generally used to set the flow rates to be released at the source according to the irrigation technique are of the order of 30 to $70 \%$, in surface irrigation [8]. In several rice-growing countries, irrigation efficiency is low, ranging from 25 to $48 \%[32,33]$. The major cause of this low efficiency is due to high lateral infiltration losses, which increase with the increase in the height of the water in the rice plot [34].

The study also showed that transplanting is poor organized over the year. The poor plot use during the first cycle would be justified by the considerable decrease in the water level of dam. Hence, the fear of rice farmers to start this cycle for which the outcome is not certain. This also justifies the low crop intensities obtained on the perimeter. Hence the urgent need to optimize leving to maintain a sufficient volume for the first cycle. Surveys and interview with rice farmers revealed the organizational problem on the irrigated area and the waste of water, which is withdrawn 24 hours a day instead of 10 hours as planned. Indeed, the volumes collected during the night are lost since no one is present on his plot after $6 \mathrm{pm}$. As the quantities of water applied are greater than necessary, it can be admitted that the irrigators take too long to water their plot [35]. Thus, negligence and ignorance of importance of water management for the maintenance of their activity is highlighted. However, one of the best ways to adapt to climate variability is to control and manage withdrawals for the different activities.

The proposed management method involves reorganizing rice activities within the irrigation area, starting with harmonizing transplanting periods for all rice farmers. The optimal transplanting period proposed for the Yamoussoukro area starts from March to April for the first cycle and September to October for the second cycle. These periods are the ones that minimize rice water needs regardless of the climate regime. They allow make the most of the rains. A curve Height-Flow-Turn of the valve has been created to facilitate the definition of the flows to be taken by the valve manager while respecting the 10 hours per day. For a flexibility in the implementation of water distribution, a telephone fleet is proposed. The telephone fleet is an innovation that facilitates access to information and dose planning.

\section{Conclusion}

Analysis of water uses for rice production shows that water is being wasted on rice growing area. Thus, the study of an optimized water withdrawal management under rainfall variability makes sense. The under-exploitation of the Nanan perimeter and its water wasted require a reorganization of farmers and an organization of water management. First step is to harmonize transplanting dates for all farmers from March to April for the first cycle and from September to October for the second cycle. In addition, the use of a Height - Flow rate - Valve turn curve is proposed to the valve manager to better evaluate the water quantities to be taken. Finally, a telephone fleet is proposed to facilitate communication and the water rotation between rice farmers.

\section{References}

[1] Servat E., Paturel J. E., Kouame B., Travaglio M., Ouedraogo M., Boyer J. F., Lubes-Niel H., Fritssch J. M., Masson J. M., Marieu B., (1998). Identification, characterization and consequences of hydrological variability in West and Central Africa. Internationale association of hydrological l sciences, 252, pp. 323-337.

[2] UNDP (2009). Poverty Reduction Support Programme of UNDP, 2009-2013, Environmental protection and sustainable management of natural resources subprogramme (PGDRN), project document, 19p.

[3] Baron C. (2009). Water in Africa: Availability and Access, New Energy of Paris, Economica. Revue futuribles $\mathrm{n}^{\circ} 359$, p33-56.

[4] FAO (2002). World Agriculture towards 2015/2030, Rome.

[5] Hirsch R. (1993). The rice and rice policies in Côte d'Ivoire), 1960-1993, Paris, Caisse Francaise de developement, 72p.

[6] Kirda C and Kanber R, 1999. Water No Longer a Plentiful Resource, Should Be Used Sparingly in Irrigated Agriculture. In: C Kirda, P Moutonnet, C Hera and DR Nielsen, eds. Crop Yield Response to Deficit Irrigation. Dordrecht, the Netherlands and Kluwer Academic Publishers.

[7] English M, 1990. Deficit Irrigation I. An Analytical Framework. J Irri Drain Eng, ASCE. 116: 399-412.

[8] Van Halsema GE and Vincent L, 2012. Efficiency and productivity terms for water management: A matter of contextual relativism versus general absolutism. Agri Wat Mgmt. 108: 9-15.

[9] Bijan N., Abdolmajid L., Masoud P. (2013), Development and Analysis of Irrigation Efficiency and Water Productivity Indices Relationships in Sprinkler Irrigation Systems, International journal of Agronomy and Plant Production. Vol., $4(3), 515-523$.

[10] Doorenbos, J. \& Pruitt, W. O. (1975). Crop water requirements, FAO Irrigation and Drainage Bulletin 24, Rome, Italie, 198p.

[11] Doorenbos J. et Pruitt W. O. (1977), Background and development of methods to predict reference crop evapotranspiration (Eto) guidelines for predicting crop water requirements. FAO irrigation and drainage paper no. 24, Rome Italy, 144p. 
[12] Allen R. G., Pereira L. S., Raes D., and Smith M. (1998). Crop evapotranspiration guidelines for computing crop water requirements- FAO, irrigation and drainage paper no. 56. FAO, Rome, Italy, 326p.

[13] Central Rice Project (1998). Technical report on the rehabilitation of the irrigated perimeter of Nanan, $45 \mathrm{p}$.

[14] OMM (1994). Data acquisition and processing, analysis, forecasting and other applications, Guide of Hydrological Practices, WMO-N 168, Edition 5, 829p.

[15] Nouvelot J. (1993). Guide to hydrological practices in small rural catchments of tropical and equatorial Africa, ORSTOM Report, 539 p.

[16] Nicholson S. E., Kim J., Hoopingarner J. (1988). atlas of African rainfall and its interannual variability. Édit. Department of meteorology, Florida State University Tallahassee, Floride, USA, 237 p.

[17] Mahe G., Olivry J. C. (1995). Precipitation and flow variations in West and Central Africa from 1951 to 1989. Sécheresse, 6 (1), pp. 109-117.

[18] Servat E., Paturel J. E., Lubes N. H., Kouame B., Masson J. M., Travaglio M., Marieu B., (1999). Different aspects of rainfall variability in non-Sahelian West and Central Africa. Revue des sciences de l'eau, 12 (2), pp. 363-387.

[19] Goula B. T. A., Kouassi F. W., Fadika V., Kouakou K. E., Kouadio G. B., Koffi K., Bamory K., Doumouya I. \& Savane I. (2009) Impacts of climate change and variability on groundwater in humid tropical zones. iash publication, 334: $190-202$.

[20] Soro T. D., Soro N., Oga Y. M. S., Lasm T., Soro G., Ahoussi K. E., Biemi J., (2011). Climate variability and its impact on water resources in the square degree of Grand Lahou (SouthWest Côte d'Ivoire), Géographie physique et environnement, Volume 5, p. 55-73.

[21] McKee T. B., Doesken N. I. and Kleist I. (1993). The relationship of drought frequency and duration to time scale. Acte of the $8^{\text {th }}$ conference on applied climatology (Anateim, californie), 179-184.

[22] Assani A. A. (1999). Analysis of the temporal variability of precipitation (1916-1996) in Lubumbashi (Congo-Kinshasa) according to some indicators of atmospheric (southern oscillation) and oceanic (El Nino/La Nina), Sécheresse, 10 (4): 245-252

[23] Smith, M. (1992). Cropwat: Software for planning and managing irrigation systems (manual and guidelines). Bulletin d'irrigation et de drainage FAO 46, Rome, Italie, 133 p.

[24] Muñoz, G., Grieser, J. (2006). Climwat 2.0 for Cropwat. Food and agricultural organization of the United Nations: Rome, Italie.

[25] Dembélé Y., Ouattara S. et Zida Z. (2000) Impact of the transplanting date of rice on the agricultural performance of small irrigated areas in Burkina Faso, Bulletin of agronomic research, $\mathrm{N}^{\circ \circ} 28$, p18-29.

[26] Keita A. and Sandwidi J. P. (1996). Water and infrastructure management for small irrigated areas in: Améliorer les performances des petits périmètres irrigués, actes seminaire régionale du projet management de l'irrigation au Burkina Faso, 24-26, IIMV/PMI-BF, MEE, Ouagadougou (Burkina Faso), 89-120.

[27] Rasool A., Zohrab S., Rhonda S. (2013) Evaluating on-farm irrigation efficiency across the watershed: A casestudy of New Mexico's Lower Rio Grande Basin, Agricultural Water Management 124, 52-57

[28] American Society of Agricultural and Biological Engineers (ASABE) Standards. Soiland Water Terminology, S526.3 SEP 2007.

[29] Dembelé Y., Ouattara, S., Kéita A., 2002. Application of the "Relative Water Supply" and "Water Productivity" indicators to small irrigated perimeters performance analysis in Burkina Faso. Irrig. and Drain. 50, 309-321.

[30] Fossou R. M. N, N Soro, VB Traore, T Lasm, S Sambou, T Soro, R. K Orou, MT Cisse, A Kane (2014). Climate variability and its impact on surface waters resources: case stations of the Bocanda and Dimbokro, East Central Côte d'Ivoire in West Africa, Afrique Science, Revue Internationale des Sciences et technologie, vol 10, 4, p118-134.

[31] Paturel J. E., Servat E. \& Delattre M. O. (1998). Analysis of long-term rainfall series in non-Sahelian West and Central Africa under climate variability. Journal des sciences hydrologiques, 43 (3): 937-945.

[32] Walker S. H., 1999. Causes of high water losses from irrigated rice fields: field measurements and results from analogue and digital models. Agric. Water Manage. 40, 123-127.

[33] Lage M., Bamouh A., Badawi T., El Mourid M., 2004. Proceedings of the seminar Modernization of Irrigated Agriculture. Rabat.

[34] Kambou D., Xanthoulis D., Ouattara K., Degré A., (2014). Concepts of Water Efficiency and Productivity (Bibliographic Synthesis). Biotechnol. Agron. Soc. Environ., 18 (1), 108-120.

[35] Kambou D., Degré A., Xanthoulis D., Ouattara K., Destain JP., Defoy S., De L'Escaille D., 2019. Evaluation and proposals for improving irrigation performance around small reservoirs in Burkina Faso. J. Irrig. Drain. Eng., 145 (6). 